\title{
Echocardiographic screening in neonates undergoing surgery for selected gastrointestinal malformations
}

\author{
R M R Tulloh, S P Tansey, K Parashar, J V De Giovanni, J G C Wright, E D Silove
}

\begin{abstract}
To compare echocardiography with clinical examination, radiography, and electrocardiography for the detection of congenital heart defects (CHD) a four year prospective study was carried out in 166 neonates with selected congenital gastrointestinal malformations (anorectal anomaly, tracheo-oesophageal fistula, duodenal atresia, exomphalos, and gastroschisis). Routine examination and investigation detected CHD in 16 neonates. Using echocardiography CHD was diagnosed in $38(23 \%)$ neonates of whom five had two gastrointestinal malformations: in $22 / 57$ (39\%) with a tracheo-oesophageal fistula, 10/67 (15\%) with an anorectal anomaly, 4/20 (20\%) with exomphalos, $6 / 20(30 \%)$ with duodenal atresia, and 1/7 with gastroschisis.

A significantly higher incidence of CHD in neonates with gastrointestinal malformations was diagnosed using echocardiography $(23 \%)$ compared with routine examination and investigation (9\%). Early diagnosis of CHD allowed a unified approach to be presented to the family. (Arch Dis Child 1994; 70: F206-F208)
\end{abstract}

The association of congenital heart defects (CHD) with congenital gastrointestinal malformations is well recognised. ${ }^{1}$ Patients with an anorectal anomaly, tracheo-oesophageal fistula, exomphalos, and duodenal atresia have a higher incidence of congenital heart disease than the general population. ${ }^{2-4}$ In previous studies echocardiographic screening has not been used. Our institution provides both regional neonatal surgical and infant cardiac services, enabling a multidisciplinary approach to these babies. Antibiotic prophylaxis can be anticipated, along with the need for careful management of fluids and oxygen when appropriate. A complete diagnosis is also important when counselling the parents of neonates with multiple complex malformations before surgery is contemplated. We therefore decided to undertake a prospective study using echocardiography to screen all children presenting in the neonatal period with the above gastrointestinal malformations.

Patients and methods

From June 1987 to November 1991, all 166 neonates admitted to the Children's Hospital, Birmingham with gastrointestinal malforma- tions requiring surgery were entered into this study. They underwent clinical examination, electrocardiography, chest radiography, and were referred for a cardiac opinion. Examination by a cardiologist and echocardiography were performed at the earliest possible date. Comparison was made between the clinical diagnosis and that suggested by the investigations. Information was stored on a database and coded.

As it is recognised that all neonates have a patent foramen ovale, an atrial septal defect was only diagnosed when there was unrestricted left to right shunting on colour flow Doppler through an atrial communication. Likewise, babies were only diagnosed as having a persistent ductus arteriosus if one was present at 1 month of age.

\section{STATISTICAL METHODS}

The comparison between the observed rate of diagnosis of CHD using clinical and electrocardiographic with radiographic examination and that using echocardiography was performed by a paired proportions $t$ test. The comparison between our observations and those in the literature were performed using a two sample $t$ test of proportions.

\section{Results}

Of the 166 neonates presenting with gastrointestinal malformations requiring surgery, 67 had an anorectal anomaly, 57 had a tracheooesophageal fistula, 20 exomphalos, seven gastroschisis, and 20 duodenal atresia. Five children were found to have two gastrointestinal malformations, three having tracheooesophageal fistula and an anorectal anomaly, and two having duodenal atresia and an anorectal anomaly. The median age of presentation was 0 days (range $0-7$ days). The cardiology team reviewed the babies at a median age of 1 day (range 0-66 days).

Clinical examination by the referring team suggested cardiac abnormality in eight cases. When chest radiography, electrocardiography, and examination by a member of the cardiology team were included, 16 of the children were considered to have CHD. However, using echocardiography, CHD were found in 38 (table 1). Thus there were 22 in whom CHD were not suspected clinically or with the assistance of routine investigations but was demonstrated on echocardiography (table 2). Thirteen of these have since proceeded to cardiac surgery. The specificity and sensitivity of the 
Table 1 Distribution of CHD with gastrointestinal malformations

\begin{tabular}{|c|c|c|c|c|c|c|c|c|c|}
\hline $\begin{array}{l}\text { Gastrointestinal } \\
\text { malformations }\end{array}$ & $\begin{array}{l}\text { No of } \\
\text { infants }\end{array}$ & $\begin{array}{l}\text { No (\%) } \\
\text { with CHD }\end{array}$ & $V S D$ & $A S D$ & $\begin{array}{l}\text { Tetralo } \\
\text { of } \\
\text { Fallot }\end{array}$ & $A V S D$ & $P D A$ & $\begin{array}{l}\text { Coarctation } \\
\text { of the } \\
\text { aorta }\end{array}$ & Other \\
\hline $\begin{array}{l}\text { Tracheo-oesophageal fistula } \\
\text { Anorectal anomaly }\end{array}$ & 57 & $22(39)$ & 3 & 6 & 4 & 1 & 5 & 2 & DORV \\
\hline $\begin{array}{l}\text { High } \\
\text { Low }\end{array}$ & $\begin{array}{l}11 \\
56\end{array}$ & $\begin{array}{l}4(36) \\
6(11)\end{array}$ & 1 & $\begin{array}{l}2 \\
1\end{array}$ & 1 & 1 & $\begin{array}{l}1 \\
3\end{array}$ & & \\
\hline Duodenal atresia & 20 & $6(30)$ & 1 & 1 & & 1 & 2 & & Absent LAVV \\
\hline Exomphalos & 20 & $4(20)$ & 1 & & 1 & & 1 & 1 & \\
\hline Gastroschisis & 7 & $1(14)$ & & & & & 1 & & \\
\hline Total & $166^{\star}$ & $38(23)$ & 6 & 10 & 5 & 3 & 9 & 3 & 2 \\
\hline
\end{tabular}

^Five neonates had two gastrointestinal malformations.

$\mathrm{VSD}=$ =ventricular septal defect; $\mathrm{ASD}=$ atrial septal defect; $\mathrm{AVSD}=$ atrioventricular septal defect; PDA=persistent ductus arteriosus; DORV=double outlet right ventricle; LAVV=left atrioventricular valve.

clinical and investigative procedures are shown in table 3. Comparing the effectiveness of the two modes of investigation, echocardiography was significantly more sensitive $(p<0 \cdot 01)$.

Of the 166 neonates, six had a ventricular septal defect, 10 had an atrial septal defect, five had Fallot's tetralogy, three had an atrioventricular septal defect (AVSD), three had coarctation of the aorta, one had double outlet right ventricle, one had an absent left atrioventricular valve, and an additional nine had persistent ductus arteriosus. All five of the neonates with two gastrointestinal malformations had cardiac abnormalities.

There were 12 children who had Down's syndrome in this study. Of these, six had congenital heart disease: one with an anorectal anomaly and an AVSD, one an anorectal anomaly and patent ductus arteriosus, one with a tracheo-oesophageal fistula and an AVSD, one with duodenal atresia and patent ductus arteriosus, and one with duodenal atresia and an AVSD. One case of Down's syndrome, who had an AVSD diagnosed on clinical examination with electrocardiography was found on echocardiography to have an absent left atrioventricular connection. The associated gastrointestinal malformation was duodenal atresia and on the basis of the complex nature of the multiple defects in this infant, the parents decided not to proceed further and treatment was withdrawn. The other neonates with duodenal atresia and CHD were confirmed not to have Down's syndrome on chromosome analysis. One neonate had pentalogy of Cantrell with exomphalos and tetralogy of Fallot. One child had trisomy 13, an anorectal anomaly and an atrial septal defect. Four children had VATER (vertebral defects, imperforate anus, tracheo-oesophageal fistula, and radial and renal dysplasia) sequence, two with tetralogy of Fallot, one with an atrial septal defect and one with patent ductus arteriosus.

Table 2 Abnormalities detected by echocardiography but not by routine clinical examination, electrocardiography, and radiography

\begin{tabular}{lll}
\hline CHD & $\begin{array}{l}\text { No of } \\
\text { infants }\end{array}$ & $\begin{array}{l}\text { No who } \\
\text { have undergone } \\
\text { cardiac surgery }\end{array}$ \\
\hline Double outlet right ventricle & 1 & 1 \\
Coarctation of the aorta & 2 & 2 \\
Ventricular septal defect & 4 & 2 \\
Atrial septal defect & 7 & 4 \\
Persistent ductus arteriosus & 8 & 4 \\
\hline
\end{tabular}

\section{Discussion}

We have found a significantly higher incidence of CHD in neonates with selected gastrointestinal malformations than previously reported. In our series, CHD were present in $39 \%$ of those with tracheo-oesophageal fistula, compared with $14 \cdot 7 \%$ reported by Greenwood and Rosenthal $(\mathrm{p}<0.05),{ }^{3}$ in $36 \%$ of those with high and $11 \%$ with low anorectal anomalies compared with a reported incidence of $12 \%$ in all those with imperforate anus ${ }^{2}$ and a similar incidence for exomphalos $(20 \%){ }^{4}$ We found a $30 \%$ incidence in duodenal atresia. It is of note that of those with two gastrointestinal malformations, all five had CHD. If the incidences reported by Greenwood et al and that in our study for tracheo-oesophageal fistula, anorectal anomaly, and exomphalos are compared, then we detected significantly more cases of CHD (24\% $v 14 \%, \mathrm{p}<0.05)$. In our study the number of cases of gastroschisis was small, not allowing suitable comparisons to be made. At the time of the previously reported series, two dimensional echocardiography with spectral and colour Doppler was not available and hence many of the diagnoses were made on clinical grounds. It is apparent that the higher incidence in our study reflects the ability to screen patients using echocardiography, as well as the trend towards early diagnosis of all congenital malformations. The current trend includes an aggressive approach towards managing and attempting to correct most congenital gastrointestinal malformations and cardiac malformations.

The diagnostic sensitivity of clinical, electrocardiographic, and radiographic investigations was low. This contrasts with the results of another recent screening survey. ${ }^{5}$ In that study the sensitivity of the investigations combined with clinical examination but excluding echocardiography was 0.71 and the specificity was 0.91 . This difference was due to the fact that in our study the clinical examinations were almost all performed on the first day of life, whereas in that study only three quarters of the

Table 3 Additive specificity and sensitivity of diagnostic tests

\begin{tabular}{lll}
\hline Diagnostic test & Sensitivity & Specificity \\
\hline 1. Clinical examination & $0 \cdot 21$ & 0.98 \\
2. + Electrocardiography & $0 \cdot 21$ & 1.0 \\
3. + Chest radiography & $0 \cdot 29$ & 1.0 \\
4. + Cardiologist's examination & 0.39 & 1.0 \\
\hline
\end{tabular}


patients were seen by 2 weeks of age. Our study reinforces our opinion that clinical examination, electrocardiography, and radiography are insufficient in the early newborn period to detect CHD.

There is a known association between some congenital gastrointestinal malformations and CHD, such as in the VATER or VACTERL (vertebral, anal, cardiac, tracheo-oesophageal, renal, and limb defects) sequence. ${ }^{6}$ Down's syndrome is likewise known to have a high incidence of $\mathrm{CHD}^{5}$ and also gastrointestinal malformations. In our study, three out of six children with duodenal atresia and CHD had Down's syndrome. There were therefore three neonates who had duodenal atresia and CHD but did not have Down's syndrome.

In a high risk group of neonates who are to undergo early surgery for gastrointestinal malformations, we recommend the following. When the neonate first presents, counselling the parents should include the information that there is a $20-30 \%$ risk of CHD. The use of electrocardiography to detect CHD is unhelpful, but most of these children will undergo radiography to investigate their associated defects. Our study shows that echocardiography is required for definitive diagnosis and should be performed at the earliest opportunity irrespective of the clinical findings. It is quick, non-invasive, and is both sensitive and specific. This would result in less clinical uncertainty, permit a team approach to the parents and allow early formation of a plan for the infant. The one relative disadvantage is that the technique needs to be performed or interpreted by someone with the required expertise. No child needed either medical or surgical treatment of their CHD before gastrointestinal surgery, but those who did require cardiac intervention were able to undergo this as an elective or semielective procedure.

\section{Conclusion}

We have confirmed a higher incidence of CHD based on echocardiography in neonates requiring surgery for gastrointestinal malformations than that detected using clinical, electrocardiographic, and radiographic examination. We therefore recommend that the increased awareness of the association between these defects should lead to echocardiographic screening at the earliest opportunity.

We are grateful to Messrs J J Corkery, P Gornall, and R Buick for kind permission to describe our findings in their patients.

1 Lubinsky M. Current concepts: VATER and other associations. Historical perspectives and modern interpretations. Am $\mathfrak{f}$ Med Genet 1986; 2 (suppl): 9-16.

2 Greenwood RD, Rosenthal A, Nadas AS. Cardiovascular malformations associated with imperforate anus. $\mathcal{F}$ Pediatr 1975; 86: 576-9.

3 Greenwood RD, Rosenthal A. Cardiovascular malformations associated with tracheo-oesophageal fistula and oesophageal atresia. Pediatrics 1976; 57: 87-91.

4 Greenwood RD, Rosenthal A Nadas AS Cardiovascular malformations associated with exomphalocele. $\mathcal{f}$ Pediatr 1974; 85: 818-21.

5 Tubman TRJ, Shields MD, Craig BG, Mulholland HC, Nevin NC. Congenital heart disease in Down's syndrome: two year prospective early screening study. BMF 1991; 302: 1425-7.

6 Knowles S, Thomas RM, Lindenbaum RH, Keeling JW, Winter RM. Pulmonary agenesis as part of the VACTERL sequence. Arch Dis Child 1988; 63: 723-6. 